ROCZNIKI HUMANISTYYCZNE

Tom LXVII, zeszyt 6 - 2019

DOI: http://dx.doi.org/10.18290/rh.2019.67.6-2

AGATA BRAJERSKA-MAZUR

\title{
LOJALNOŚĆ TŁUMACZA
}

Spór o lojalność tłumacza sięga doby Renesansu, w której jego twórczej funkcji ${ }^{1}$ propagowanej przez starożytnych (np. Cycerona, Horacego, Kwintyliana ${ }^{2}$ ) zaczęto przeciwstawiać odtwórczą rolę kopisty - zwłaszcza w odniesieniu do przekładów Biblii i dzieł teologicznych. Tłumacząc literaturę piękną, dzieła historyków i mówców nadal jednak preferowano niczym nie skrępowaną swobodę - ,[d]zieło obce miało być więc tylko zbiorem materiałów czy 'pożywienia",3. Tę zasadę

różni teoretycy różnie określali: jako „korzystanie” z klasyków, jako „pożyczanie” od nich, „łupienie” ich czy po prostu „okradanie”. Nie to było ważne, w jakim stosunku nowe dzieło pozostawało do dawnego, ale to, czy było dobre: czy przydawało blasku rodzimemu piśmiennictwu, czy się przyczyniało do rozwinięcia języka. Granica między przekładem, parafrazą, naśladownictwem a utworem oryginalnym była płynna i nieistotna ${ }^{4}$.

Dr hab. AgATA BRAJERSKA-MAZUR - adiunkt Zakładu Lingwistyki Stosowanej, Instytut Germanistyki i Lingwistyki Stosowanej UMCS; adres do korespondencji: Uniwersytet Marii Curie-Skłodowskiej, Dom Studenta Kronos, ul. Sowińskiego 17, Lublin; e-mail: a.bm@poczta. umcs.lublin.pl

${ }^{1}$ Pojęcie tłumacza jako drugiego autora rozpowszechniła dopiero Anna LEGEŻYŃSKA (Tłumacz jako „drugi autor”, w: TEJŻE, Tłumacz i jego kompetencje autorskie, Warszawa: PWN 1986, s. 20-30; TEJŻE, Tłumacz jako drugi autor - dziś, w: Przekład literacki: teoria historia, wspótczesność, red. A. Nowicka-Jeżowa i D. Knysz-Tomaszewska, Warszawa: PWN 1997, s. 40-50). Starożytni używali terminu „mówca” (Cycero: „nec converti ut interpres, sed ut orator” / „nie jak tłumacz, ale jak mówca”. Cyt. za: P. GrzegorCZyK, Problematyka ttumaczeń, w: O sztuce ttumaczenia, red. M. Rusinek, Wrocław: Ossolineum 1955, s. 446).

${ }^{2}$ Zob. P. GRZEGorCZYK, Problematyka tłumaczeń, s. 445-447.

${ }^{3}$ W. Borowy, Dawni teoretycy ttumaczeń, w: O sztuce ttumaczenia, s. 23.

4 Tamże, s. 23-24. 
Dopiero wiek XVIII osłabił twórczą rolę tłumacza i ograniczył jego swobodę ${ }^{5}$. Wiek XIX - zwłaszcza w Niemczech - jeszcze mocniej upominał się o tę granicę, znacznie wyraźniej odchodząc od francuskiej tradycji les belles infidèles i bezceremonialnej przeróbki tekstu. Friedrich Schleiermacher w swoim sławnym wykładzie $O$ różnych metodach tłumaczenia ${ }^{6}$ wygłoszonym w 1813 roku wyróżnił dwie metody przekładu. Twierdził, iż „by pomóc czytelnikom poprawnie i w pełni zrozumieć autora oryginału i zasmakować w jego dziele”, tłumacz ma tylko dwa wyjścia: albo „pozostawić, na ile to możliwe, w spokoju autora i poprowadzić ku niemu czytelnika, albo pozostawić, w miarę możliwości, w spokoju czytelnika, by poprowadzić ku niemu autora"7. Pierwszą z tych metod nazywa się współcześnie wyobcowaniem $^{8}$, egzotyzacja, defamiliaryzacja albo przektadem opornym; druga - przyswojeniem $^{9}$, udomowieniem, adaptacja albo przekładem przezroczystym. Obydwie zostały poddane wnikliwej analizie przez Schleiermachera, który bardzo wyraźnie opowiedział się za wyobcowaniem. Obcość przekładu - tj. podprowadzanie czytelnika ku autorowi oryginału - pozwala według niego na „możliwie dokładne poznanie i zasmakowanie samych dzieł" ${ }^{10}$, których rozumienie jest „zjawiskiem znanym i ze wszech miar pożądanym”, ponieważ „wpływa na duchowy rozwój narodu” i „bez wątpienia dostarcza przyjemnych wrażeń" ${ }^{11}$. Przyswojenie - tj. przybliżanie autora do czytelnika i tłumaczenie w taki sposób, jakby przekładane dzieło powstało od razu w języku tłumaczenia i nie wydawało się obce - jest zdaniem Schleiermachera nie tylko „dziełem pożądliwości i pychy"12, ale po prostu bezcelowe:

\footnotetext{
${ }^{5}$ Por. J. ZIĘTARSKA, Etyka - estetyka - filologia. U źródeł dawnej myśli translatorskiej, w: Przekład literacki, s. 29-39, gdzie autorka „spór o niedosłowność przekładania” umieszcza głównie w XVII i XVIII wieku.

${ }^{6}$ Fragmenty wykładu przetłumaczone przez P. Bukowskiego w: „Przekładaniec” 20(2009), s. $8-29$.

7 Tamże, s. 17.

8 Tj. „foreignizing” (zob. L. VENUTI, Rethinking Translation. Discourse, Subjectivity, Ideology, London \& New York: Routledge 1992; TEGOŻ, The Translator's Invisibility. A History of Translation, London \& New York: Routledge 1995; TEGOŻ, The Scandals of Translation. Towards an Ethics of Difference, London \& New York: Routledge 1998).

${ }^{9} \mathrm{Tj}$. „domesticating” (L. VENUTI, Rethinking Translation; TEGOŻ, The Translator's Invisibility; TEGOŻ, The Scandals of Translation).

10 „Przekładaniec” 20(2009), s. 27.

11 Tamże, s. 23.

12 Tamże, s. 27.
} 
Można nawet powiedzieć, że cel: tłumaczyć tak, jak autor napisałby oryginalnie w języku przekładu, jest nie tylko nieosiągalny, ale także sam w sobie błahy i nieistotny ${ }^{13}$.

Mimo postulatów Schleiermachera tłumacze nadal jednak do tej pory (zwłaszcza w kulturze anglojęzycznej) znacznie częściej sięgają po strategię przyswojenia niż wyobcowania, co zauważył Lawrence Venuti ${ }^{14}$ : sam będący gorącym zwolennikiem egzotyzacji, czyli wierności wobec tekstu oryginału, jego autora, języka i kultury.

Spór o lojalność tłumacza - tj. komu i czemu ma być on wierny - jest więc odwieczny. Czy ma być lojalny wobec tekstu oryginału i/lub jego autora, a co za tym idzie, wobec kultury i języka wyjściowego, bądź też raczej wobec języka i kultury docelowej? Który czytelnik - pierwowzoru czy przekładu - jest ważniejszy i jaką wobec tego strategię - przyswojenia czy wyobcowania - ma przyjąć tłumacz? Te kwestie, zawsze pogmatwane i zależne od czasów, gustów, mody i postaw życiowych dyskutantów, od drugiej połowy XX wieku do chwili obecnej stały się jeszcze bardziej zawiłe i (ze względów, które naświetlę później) ogromnie istotne. Proponuję zatem przyjrzeć się im dokładniej od momentu powstania dyscypliny Translation Studies z uwzględnieniem kilku poprzedzających ją dekad.

Po ukonstytuowaniu się translatoryki jako dziedziny nauki w latach 70 . XX wieku nasiliły się spory o najważniejszy element w układzie translacyjnym, czyli m.in. o to, gdzie umiejscowić lojalność tłumacza - tj. komu i czemu ma on dochować wierności. Dysputy stały się bardziej zawiłe i zagmatwane, ponieważ jakkolwiek o wierności w tłumaczeniu rozprawiano już od czasów starożytnych, do lat 70 . XX wieku zawsze robiono to w odwołaniu do tekstu oryginału i jego autora. $W$ dzisiejszych czasach zaś ten odnośnik nie jest już tak oczywisty, stał się zmienny i bywa przesuwany na zupełnie inne elementy w procesie translacyjnym, w zależności od teorii czy szkoły przekładu.

Franciszek Grucza ${ }^{15}$ w następujący sposób przedstawia ów proces:

\footnotetext{
13 Tamże.

${ }^{14}$ L. VENUTI, The Translator's Invisibility.

${ }^{15}$ F. GRUCZA, Zagadnienia translatoryki, w: Glottodydaktyka a translatoryka, red. F. Grucza, Warszawa: Wydawnictwa Uniwersytetu Warszawskiego 1981, s. 9-29; TEGOŻ, Wyodrębnienie się, stan aktualny i perspektywy świata translacji oraz translatoryki, „Lingua Legis” 1998, nr 6, s. 2-12.
} 
TRANSLACJA

Nadawca $\rightarrow$ Tekst $\mathrm{A} \rightarrow$ Odbiorca pośredni $\rightarrow$ Nadawca pośredni $\rightarrow$ Tekst $\mathrm{B} \rightarrow$ Odbiorca inicjalny

Schemat 1. Układ translacyjny

finalny

Wygodniej jednak będzie nieco zmodyfikować jego schemat i inaczej nazwać poszczególne elementy układu, by bardziej uwyraźnić dylematy tłumacza:

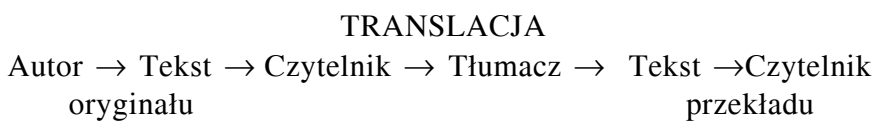

Schemat 2. Układ translacyjny (Brajerska-Mazur 2017)

W tym schemacie tłumacz jest zarazem odbiorca oryginału, jak i nadawca inicjującym przekład, pośredniczy między językiem i kulturą wyjściową (pierwsze trzy elementy układu) a kulturą i językiem docelowym (dwa ostatnie). Któremu elementowi ma zatem dochować wierności? Jeszcze w latach 50. i 60., kiedy uważano translatorykę za dziedzinę językoznawstwa, nadal był nim autor i tekst oryginału. Lingwiści, semiotycy i strukturaliści (Jakobson, Nida, Levý, Popovič, Ingarden), mimo podkreślania wagi także innych elementów układu translacyjnego ${ }^{16}$, ciągle jeszcze domagali się lojalności wobec pierwowzoru i intencji jego twórcy. Potępiliby zatem np. przekład Fatum Norwida dokonany przez Adama Czerniawskiego w 1973 roku, a przyklasnęliby jego tłumaczeniu tego samego wiersza z roku 2004 jako temu, który jest strukturalnie i semantycznie wierny wobec oryginału ${ }^{17}$.

\footnotetext{
${ }^{16}$ Nida i Popovič podkreślali wagę odbiorcy przekładu, Levý zaś tłumacza i jego procesów decyzyjnych. Zob. P. BuKowski, M. HeYdel, Przekład - język - literatura, w: Wspótczesne teorie przektadu. Antologia, red. P. Bukowski i M. Heydel, Kraków: Znak 2009, s. 7-13, oraz T. BILCZEWSKI, Komparatystyka i interpretacja. Nowoczesne badania porównawcze wobec translatologii, Kraków: Universitas 2010.

${ }^{17}$ Przekład Czerniawskiego z 1973 roku analizowałam bardzo szczegółowo w: Trzy tłumaczenia „Fatum” na jezzyk angielski, „Studia Norwidiana” 14(1996), s. 65-94, a także w książce $O$ angielskich ttumaczeniach utworów Norwida, Lublin: TN KUL 2002, s. 71-102; natomiast tłumaczenie z 2004 roku w: Adam Czerniawski $i$, Selected Poems” Norwida, „Studia Norwidiana" 22(2004), s. 293-308.
} 
Norwid: I

Jak dziki zwierz przyszło $\mathrm{N}$ i e s z c z ę ś c i e do człowieka I zatopiło weń fatalne oczy...

- Czeka - -

Czy, człowiek, zboczy?

II

Lecz on odejrzał mu, jak gdy artysta

Mierzy swojego kształt modelu;

I spostrzegło, że on patrzy - c o? skorzysta

Na swym nieprzyjacielu:

I zachwiało się całą postaci wagą

-- I nie ma go! ${ }^{18}$

A.Cz. $1973^{19}$ :

\begin{tabular}{|l|l|}
\hline $\begin{array}{l}\text { Like a wild beast tragedy startled a man } \\
\text { And pierced him with her fateful eyes } \\
\text { - Waiting - }\end{array}$ & $\begin{array}{l}\text { Jak dzika bestia tragedia zaskoczyta cztowieka } \\
\text { I przeszyla go fatalnymi oczyma } \\
- \text { Czekajac }-\end{array}$ \\
Czy zboczy?
\end{tabular}

A.Cz. $2004^{20}$ :

${ }^{18}$ Cyt. za: C. NorwID, Pisma wszystkie, zebrał, tekst ustalił, wstępem i przypisami opatrzył J.W. Gomulicki, t. I-XI, Warszawa 1971-1976. Tu t. II, s. 49.

${ }^{19}$ Polish Poetry Supplement, No. 7, „Oficyna Poetów”, No. 2 (29), London, May 1973, s. 17.

${ }^{20}$ Cyprian Kamil Norwid, Selected Poems, translated by A. Czerniawski, London: Anvil Press 2004, s. 67. 


\begin{tabular}{|l|l|}
\hline $\begin{array}{l}\text { Misfortune, like a wild beast, accosted man } \\
\text { And pierced him with its fateful eyes... } \\
\text { - Waits - - }\end{array}$ & $\begin{array}{l}\text { [Nieszczę́scie, jak dzika bestia, przystąiło } \\
\text { do człowieka } \\
\text { I przeszyło go fatalnymi oczyma } \\
\quad \text { Czekając - } \\
\text { Czy człowiek zboczy? }\end{array}$ \\
$\begin{array}{l}\text { But he gazed back like an artist } \\
\text { Who sizes up his model's form; } \\
\text { Noticing that he looks - how? to profit } \\
\text { From his foe: } \\
\text { It staggered with all its weight } \\
-- \text { And is gone! }\end{array}$ & $\begin{array}{l}\text { Lecz on odejrzał mu jak artysta } \\
\text { Który mierzy kształt swojego modelu; } \\
\text { Zauważając, że on patrzy - jak? wykorzy- } \\
\text { stać } \\
\text { Swojego wroga: } \\
\text { Zachwiało się całą swoją wagą } \\
- \text { - I nie ma go!] }\end{array}$ \\
\hline
\end{tabular}

Zupełnie inaczej wartościowałyby przywołane tłumaczenia niemiecka szkoła przekładu oraz teorie skupione wokół Translation Studies, ponieważ zdetronizowały one oryginał jako najważniejszy punkt odniesienia zarówno w procesie translacyjnym, jak i w przesądzaniu o lojalności tłumacza. Ze szkoły niemieckiej ${ }^{21}$ jako najbardziej wywrotowa $w$ charakterze jawi się funkcjonalistyczna teoria Hansa Vermeera i Kathariny Reiss. Otóż ci badacze twierdzą, iż „tekst wyjściowy i jego język nie mogą być absolutną miarą przekładu" ${ }^{22}$, ponieważ przyjęli ogólną teorię działania (tj.: „każde działanie jest określone przez swój cel") za naczelną zasadę każdego przekładu, który jest według nich „funkcją swojego celu” ${ }^{23}$. Owa reguła, nazwana regułą skoposu (z gr. skopós - cel, znacznik, intencja, funkcja), została wyrażona za pomoca formuły: „Cel uświęca środki” "24. „Oznacza to, że w procesie translacji osiągnięcie danego celu tłumaczeniowego jest znacznie ważniejsze od tego, czy proces ten został zrealizowany we 'właściwy'25 sposób. Działanie translatorskie ma zatem, zgodnie z teorią skoposu, charakter intencjonalny i final-

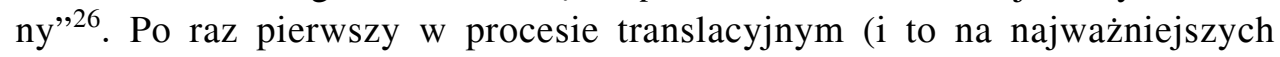
pozycjach!) pojawili się: CEL przekładu i jego ZLECENIODAWCA. Jeśli

\footnotetext{
${ }^{21}$ Czytelnik znajdzie wiele informacji o tej szkole w: P. BuKowsKI, M. HEYDEL, Przektad - jezyk - literatura, s. 14-20.

${ }^{22}$ H. VERMEER, Die sieben Grade einer Translationstheorie, ,Studia Germanica Posnaniensia" 2003, vol. 29, s. 24. Wyróżnienie moje - A.B.-M.

${ }^{23}$ K. REIß, H. VERMEER, Grundlegung einer allgemeinen Translationstheorie, Berlin: Walter de Gruyter 1984.

${ }^{24}$ Tamże, s. 101.

25 Tamże, s. 100.

${ }^{26}$ P. BuKowski, M. Heydel, Przektad - jezzk - literatura, s. 18. Por. J. KozAK, Kot bez uśmiechu czy(li) uśmiech bez kota?, „Przekładaniec” 7(2000), s. 9-27.
} 
tłumacz zrealizuje zlecenie (np. przerobi Hamleta na kukiełkową komedię gejowską po czesku) - osiągnie swój cel, zachowa lojalność wobec sponsora, więc jego przekład trzeba ocenić jako udany.

Nie tylko konsekwentny funkcjonalizm jest równoznaczny z „detronizacją tekstu wyjściowego" ${ }^{27}$, ale także niektóre szkoły skupione wokół Translation Studies, które usytuowało translatorykę jako odrębną dziedzinę nauki, przesuwając jednocześnie ,punkt ciężkości w badaniach nad przekładem z zagadnień czysto językoznawczych na kwestie kulturowe, ze szczególnym uwzględnieniem przekładu literackiego" ${ }^{28}$. Nazwa Translation Studies pochodzi od tytułu wystąienia amerykańskiego badacza Jamesa Holmesa The Name and Nature of Translation Studies, które wygłosił w 1972 roku w Leuven. W tymże referacie Holmes postulował stworzenie odrębnej nauki o przekładzie, której wewnętrzne podziały i pola badawcze szczegółowo opisał ${ }^{29}$. Teoretycy z kręgu TS (Holmes, André Lefevere, Frans de Haan) uważali tekst tłumaczenia za fakt kultury docelowej, analizowali więc przede wszystkim ostatnie elementy schematu translacyjnego: język, kulturę i odbiorców przekładu. Przestało być ważne czy tłumacz jest lojalny wobec oryginału i jego twórcy, bowiem ważniejsza stała się jego lojalność wobec czytelnika i kultury przekładu. Ten trend uwyraźnił się jeszcze bardziej w teorii i badaniach postulowanych przez izraelskich uczonych: Itamara Even-Zohara i jego ucznia Gideona Toury. Proponowali oni, by zastąpić pojęcie ekwiwalencji (odpowiedniości/wierności) tłumaczenia wobec pierwowzoru pojęciem jego AKCEPTOWALNOŚCI ${ }^{30}$ w kulturze docelowej.

Poziom akceptowalności przekładu opisać można, odnosząc się do obowiązujących w kulturze docelowej norm. [...] Toury definiuje normy jako pewne prawidłowości zachowań przekładowych wynikające z wpływających na poziom akceptowalności przekładów ograniczeń społeczno-kulturowych, tworzących skalę rozciągającą się pomiędzy anarchią a ścisłymi regułami. Przesunięcia i różnice wobec oryginału są w przekładzie nieuniknione, a sama ocena adekwatności, czyli krytyka przekładu, także jest funkcją norm obowiązujących w kulturze docelowej.

${ }^{27}$ H. VERMEER, Übersetzen als kultureller Transfer, w: Übersetzungswissenschaft - Eine Neuorientierung. Zur Integrierung von Theorie und Praxis, red. M. Snell-Hornby, Tübingen: Francke 1986, s. 42.

${ }^{28}$ P. Bukowski, M. Heydel, Przektad - jezyk - literatura, s. 20. Por. E. Gentzler, Contemporary Translation Theories, wyd. 2, Clevendon: Multilingual Matters 2001, s. 77.

29 Zob. J. Holmes, The Name and Nature of Translation Studies, w: The Translation Studies Reader, red. L. Venuti, London \& New York: Routledge 2004, s. 172-186.

${ }^{30}$ G. TOury, Descriptive Translation Studies - and Beyond, Amsterdam-Philadelphia: John Benjamins 1995, s. 53-54. 
Przedmiotem badania jest tu zatem obszar kultury i rządzące nim prawidłowości, a nie odsunięta na daleki margines sprawa „wierności” przekładu wobec oryginału. Normy pełnią wobec indywidualnych tłumaczy funkcję dyrektyw co do poziomu społecznej akceptacji dla wypowiedzi, stylów i poetyk. Oznacza to, że stosowanie się do istniejących norm daje gwarancję akceptacji, a więc uznania przekładu za tekst kultury docelowej. Sprzeciwienie się normie, które może wynikać z etycznej postawy thumacza respektującego autonomię oryginału i stawiającego sobie za cel stworzenie tekstu adekwatnego wobec pierwowzoru, może być gestem twórczym, prowadzącym do rewizji norm lub stworzenia nowej wartości literackiej, ale niebezpiecznym, bo grożącym odrzuceniem ${ }^{31}$.

Najlepszą ilustracją takiego procesu na gruncie literatury polskiej jest przekład Winnie the Pooh Alana Alexandra Milne'a dokonany przez Monikę Adamczyk, poprzez który tłumaczka chciała w dużo wierniejszy niż Irena Tuwim sposób oddać przygody pluszowego misia. Krytyka tego tłumaczenia była druzgocąca ${ }^{32}$, bowiem czytelnikom przekładu o wiele bardziej podobał się udomowiony przez Tuwim Kubuś Puchatek ${ }^{33}$, przystosowany do polskich norm dla literatury dziecięcej, niż lojalniejsza wobec autora oryginału i jego kultury Fredzia Phi-Phi ${ }^{34}$. Nieważne było, że przekład M. Adamczyk był wierny wobec pierwowzoru - dla odbiorców istotniejsza okazała się lojalność wobec norm kultury docelowej, do których I. Tuwim tak bardzo dostroiła swoje tłumaczenie, iż stało się przekładem kanonicznym - zakorzenionym w świadomości czytelników do tego stopnia, iż traktują je jak tekst napisany od razu w swoim ojczystym języku i do niego, a nie do oryginału, odnoszą inne tłumaczenia książki o małym misiu ${ }^{35}$. Sprawę tę najlepiej podsumowała Monika Woźniak ${ }^{36}$ :

\footnotetext{
${ }^{31}$ M. HeYDEL, Zwrot kulturowy w badaniach nad przekładem, „Teksty Drugie” 2009, nr 6, s. 24-25. Podkreślenia moje - A.B.-M.

${ }^{32}$ Bardzo szczegółowo piszę o tym w: Kubuś czy Fredzia? Między niedostownościa a dostownościa w przektadzie imienia Winnie-the-Pooh, w: (Nie)dostowność w przektadzie. Od literatury dziecięcej po teksty specjalistyczne, red. J. Dybiec-Gajer, Kraków: Tertium 2015, s. 83-92. Tam podana obszerna literatura przedmiotu.

33 A.A. Milne, Kubuś Puchatek, tłum. I. Tuwim, Warszawa: J. Przeworski 1938.

34 A.A. Milne, Fredzia Phi-Phi, tłum. M. Adamczyk, Lublin: Wydawnictwo Lubelskie 1986.

${ }^{35}$ Definicję przekładu kanonicznego podaje E. RAJEWSKA, Zakorzenienie przekładu a polskie ttumaczenia „Winnie-the-Pooh” Alexandra Alana Milne'a, w: Przekład w historii literatury, (Studia o przekładzie, 12), red. P. Fast, K. Żemła, Katowice: Wydawnictwo Naukowe „Śląsk” 2002, s. 69.

${ }^{36}$ M. WoźNIAK, Puchata przepustka do stawy. Pochwała Ireny Tuwim, „Przekładaniec” 26(2012), s. 127.
} 
Czytelnicze protesty i zajadłe ataki na Fredzię Phi-Phi w przeważającej części wynikały nie tyle z obiektywnej analizy nowej propozycji przekładowej, ile z odebrania jej jako próby odbrązowienia poprzedniej wersji, szargania świętości narodowej. Dla wielbicieli Kubusia i Prosiaczka, przerzucających się cytatami z książki w codziennych rozmowach, kojarzących książkę z najmilszymi wspomnieniami dzieciństwa, alternatywna wersja była nie tylko niepotrzebna, ale wręcz bluźniercza.

Badając tłumaczoną literaturę, I. Even-Zohar pomija jej stosunek do oryginału, ponieważ traktuje ją jako jeden z systemów wchodzących do polisystemu literatury i języka kultury docelowej. Według niego miejsce literatury tłumaczonej może być centralne lub peryferyjne, a jej oddziaływanie innowacyjne lub konserwatywne, w zależności od tego, jak sytuuje się wobec obowiązujących w danej literaturze norm. Ponadto, w trzech różnych przypadkach, przekład może zając centralną pozycję w polisystemie literatury, w którą jest włączany. Staje się ,integralną częścią nowatorskich sił polisystemu” i zaczyna być kojarzony ,z istotnymi procesami zachodzącymi w historii danej literatury" ${ }^{\prime 3}$ wtedy:

1. kiedy polisystem jeszcze się nie skrystalizował, to znaczy kiedy literatura jest „młoda”, trwa proces jej powstawania;

2. kiedy literatura jest albo ,peryferyjna” (w obrębie dużej grupy skorelowanych literatur), albo „słaba”, albo też przejawia obie te cechy;

3. kiedy w dziejach literatury następują punkty zwrotne, momenty kryzysowe lub kiedy tworzy się w niej pewnego rodzaju próżnia literacka ${ }^{38}$.

Według powyższych kryteriów literatura polska na tle np. bardzo silnej literatury angielskiej jawi się jako literatura słaba i peryferyjna, więc tłumaczenia mają w niej wysokie miejsca i wpływają na nią ${ }^{39}$.

Propozycje badawcze I. Even-Zohara mogą być również pomocne w wyjaśnianiu czytelniczych oczekiwań wobec przekładu różnego typu literatury

${ }^{37}$ I. EVEN-ZoHAR, Miejsce ttumaczonej literatury w polisystemie literackim, w: Wspótczesne teorie przektadu, s. 198.

38 Tamże, s. 199.

39 „Since peripheral literatures in the Western Hemisphere tend more often than not to be identical with the literatures of smaller nations, as unpalatable as this idea may seem to us, we have no choice but to admit that within a group of relatable national literatures, such as the literatures of Europe, hierarchical relations have been established since the very beginnings of these literatures” (I. Even-Zohar, Polisystem Studies, „Poetics Today” 11(1990), nr 1, s. 48). Zob. również D. GutTFELD, Genre Definitions and Characteristics as Indications of Problem Areas in Translation of Science Fiction and Fantasy, „Zeszyty Naukowe UMK” (English Studies XIV) 2005, s. 151. 
oraz jej miejsca w danym polisystemie. Na przykład, w polskiej kulturze tłumaczenia literatury fantasy zajmują dość wysoką i bardzo specyficzną pozycję, ponieważ ten gatunek był obcy na gruncie polszczyzny i jako obcy (i to podwójnie obcy) został wchłonięty i zaakceptowany przez nasz polisystem literacki. Obcy nie tylko dlatego, że traktuje o wyimaginowanych światach, ale także dlatego, że w Polsce literatura fantastyczna nie była powszechnie znana i uprawiana. Stąd czytelnicy fantasy (odwrotnie niż odbiorcy tłumaczeń literatury dziecięcej) domagają się obcości - tj. forenizacji w przekładzie ${ }^{40}$. Uwielbiaja np. egzotyzujące tłumaczenie trylogii Johna R.R. Tolkiena The Lord of the Rings pióra Marii Skibniewskiej ${ }^{41}$, a odrzucają udomowienia i spolszczenia dokonane we Władcy Pierścieni przez Jerzego Łozińskiego ${ }^{42}$. Wystarczy choćby zajrzeć do Internetu na strony fanów fantasy, żeby przekonać się, iż w ich nomenklaturze „łozizmy”, „po łozińsku” i „tłumok” to eufemistyczne określenia bardzo złych tłumaczeń i kiepskich tłumaczy ${ }^{43}$.

Szkoła Manipulistów (Manipulation School), której nazwa nawiązuje do tytułu pracy zbiorowej The Manipulation of Literature $^{44}$ z 1985 roku, bada wpływ na kształt przekładu nie tylko czytelniczych oczekiwañ ${ }^{45}$. Manipulizm analizuje uwikłania translacji w różnorakie „struktury władzy, interesy narodowe, systemy religijne oraz ekonomię, których działaniom na różnych płaszczyznach podlega tłumacz"46. Czołowy przedstawiciel tej szkoły: André Le-

${ }^{40}$ Zob. D. GUTTFELD, Anglocentryzm w polskich ttumaczeniach anglojęzycznej fantastyki: tendencje, przyczyny i skutki, w: Językowy obraz świata $w$ oryginale i przekładzie, red. K. Hejwowski, A. Szczęsny, Warszawa: Uniwersytet Warszawski 2007, s. 151-157; TEJŻE, EnglishPolish Translation of Science Fiction and Fantasy, Torun: Grado 2008, s. 71-87; D. KUREK, Translators' Strategies in the Rendition of Language Varieties in Polish Versions of Selected English Fantasy Novels, rozprawa doktorska, Lublin: UMCS 2014, praca w manuskrypcie.

${ }^{41}$ J.R.R. TOLKIEN, Władca pierścieni, tłum. M. Skibniewska, Warszawa: Czytelnik 19611963.

42 J.R.R. TOLKIEN, Władca pierścieni, tłum. J. Łoziński, Warszawa: Zysk i S-ka 19961997.

${ }^{43}$ www.tłumok.republika.pl/lozins1.htm, www.tolkien.cyberdusk.pl/ index.php?tlu, www.t1 umok.republika.pl/lozins2.htm, www.tłumok.republika.pl, www.prorok.pl/tolkien/art-34.0.html, http://home.agh.edu.pl/ evermind/jrrtolkien/nprzeklad.htm,http://home.agh.edu.pl/ evermind/gan01.htm.

44 The Manipulation of Literature: Studies in Literary Translation, red. Th. Hermans, London: Croom Helm 1985.

${ }^{45}$ Badam je w: Manipulizm a wptyw czytelników na polskie ttumaczenie „Harry’ego Pottera”, „Roczniki Humanistyczne” 63(2015), z. 6, s. 151-165.

${ }^{46}$ P. Bukowski, M. Heydel, Przekład - jezyk - literatura, s. 25. 
fevere w książce Translation - History - Culture: A Sourcebook ${ }^{47}$ opisywał i podawał wielorakie przykłady manipulacji przekładem m.in. poprzez swoiście pojęte ${ }^{48}$ ideologie, patronat, tradycje artystyczne krajów docelowych oraz ich obyczajowość. Według Lefevere’a „przekłady nie powstają w próżni”49, a oryginały ulegaja w tłumaczeniu tzw. „refrakcji”, ${ }^{\circ}$ - tj. przekształceniom przy przeniesieniu $w$ inny system literacki, inny język i inną kulturę. Tak jak promień światła, który ulega załamaniu przy przejściu z jednego ośrodka w drugi, tak tekst literacki przekształca się w tłumaczeniu pod wpływem różnych mniej lub bardziej widocznych czynników zewnętrznych, takich jak np.

krytyka literacka, adaptacja, antologizacja [...], które w jakiś sposób manipulują znaczeniem tekstu wyjściowego. Działania te zawsze podporządkowane są władzy instytucji sprawujących kontrolę nad tłumaczem czy krytykiem, zasadniczo przy pomocy narzędzi ekonomicznych i politycznych, a nie wyłącznie kulturowych, takich jak obowiązujące $w$ danej kulturze wzorce i normy stylistyczne. Lefevere określa tę kontrolę mianem „patronatu” ${ }^{51}$.

Na gruncie literatury polskiej do tych najbardziej oczywistych przypadków manipulacji przekładem należą np.: spowodowana poprawnością polityczną zmiana tytułu kryminału Agathy Christie z Dziesięciu małych Murzynków na I zostat tylko jeden, czy ukrycie nazwiska tłumacza i nazwy wydawnictwa, zaangażowanych w polską publikację objętych fatwą Szatańskich wersetów Salmana Rushdiego. Równie wyraźnym przykładem manipulacji tłumaczeniem są kolejne polskie wydania Mistrza i Małgorzaty Michaiła Bułhakowa ${ }^{52}$,

\footnotetext{
${ }^{47}$ Translation - History - Culture: A Sourcebook, oprac. A. Lefevere, London: Routledge 2002.

${ }^{48}$ Zob. wyjaśnienia w: Routledge Encyclopedia of Translation Studies, red. M. Baker, G. Saldanha, London: Routledge 2011, s. 241-24.

49 Translation - History - Culture, s. 14.

${ }^{50}$ Zob. P. BuKowski, M. Heydel, Przekład - język - literatura, s. 23-24; hasło: rewriting w Routledge Encyclopedia of Translation Studies. W późniejszych pracach tym terminem Lefevere zastąpił określenie „refrakcja”.

${ }^{51}$ M. HEYDEL, Zwrat kulturowy, s. 25-26.

${ }^{52}$ Począwszy od 1969 roku książka była przekładana przez sześciu różnych tłumaczy (zob. http://encyklopediafantastyki.pl/index.php?title= Mistrz_i _Ma\%C5\%82gorzata). Najbardziej wyraźnym przejawem wpływu cenzury na tłumaczenie Mistrza i Małgorzaty jest publikacja przekładu Ireny Lewandowskiej i Witolda Dąbrowskiego w wydaniu Agory wzbogaconym w 2012 roku o unikalne zapiski żony autora z ostatnich dni jego życia oraz z zaznaczeniem fragmentów, w które ingerowała cenzura przy pierwszym wydaniu (tj. w 1969 roku).
} 
z których w czasach komunizmu usuwane były całe fragmenty tekstu, dodawane później w publikacjach powstałych po 1989 roku.

Wpływ szeroko pojętego patronatu (ideologicznego, ekonomicznego i klasowego) został opisany w artykule Katarzyny Szymańskiej ${ }^{53}$, w którym badaczka podała inne konkretne przykłady manipulacji w tłumaczeniach na język polski i z języka polskiego. Paulina Biały ${ }^{54}$ opisywała z kolei jak religia i ideologia zmieniają treść i przesłanie europejskich bajek przekładanych na języki arabskie. Ja natomiast, w osobnych publikacjach, pokazywałam wpływ czytelniczych oczekiwań na polskie tłumaczenie serii książek o Harrym Potterze oraz oddziaływanie cenzury i sytuacji politycznej na przekład i odbiór wierszy Zbigniewa Herberta w krajach anglojęzycznych ${ }^{55}$.

Przykłady czynników zewnętrznych wywierających wpływ na kształt przekładu można by mnożyć bez końca ${ }^{56}$. Trzeba jednakże pamiętać, że pokazując je, badacze nie manipulują translacją, lecz ujawniają realne naciski, od których zależy nie tylko forma tłumaczenia, ale nawet jego zaistnienie. Tropiąc te naciski, coraz bardziej traci się jednak z oczu powiązanie przekładu $\mathrm{z}$ oryginałem, bowiem punkt ciężkości analizy zostaje przesunięty nawet nie na ostanie elementy układu translacyjnego, ale na ich otoczenie. W schemacie tłumaczeniowym obok przekładu, jego języka, kultury i odbiorców pojawiaja się: zleceniodawca, cenzura, ideologia, religia, polityka itp.

Jeszcze bardziej od oryginału oddalają się zwolennicy dekonstrukcjonizmu, którzy uważają, że przekład jest znacznie ważniejszy od pierwowzoru, nadaje mu bowiem drugie życie ${ }^{57}$. Każda interpretacja tekstu źródłowego jest według nich właściwa i uprawniona, a tłumacz ma prawo do dowolnych zmian wobec ostatecznie zdetronizowanego oryginału. Miarą jego lojalności jest... on sam, ponieważ staje się drugim (i ważniejszym) autorem tekstu.

\footnotetext{
${ }^{53}$ K. SZYMAŃSKA, Przekład literacki - manipulacja: refrakcja i instytucja patronatu wedtug André Lefevere'a i Manipulation School, „Polisemia” 2010, nr 2, http://www.polisemia. com.pl/numery-czasopisma/numer-2-2010-2/przeklad-literacki---manipulacja.

${ }^{54}$ Dydaktyzm i cenzura $w$ ttumaczeniu literatury dziecięcej $w$ świecie arabskim, w: Stowo kontekst - przektad, red. J. Dybiec-Gajer i A. Tereszkiewicz, Kraków: Tertium 2014, s. 71-80.

55 A. BRAJERSKA-MAZUR, Manipulizm a wpływ czytelników na polskie tłumaczenie „Harry'ego Pottera”, s. 151-165; TEJŻE, „Polityczność, ,polskość” i uniwersalność wierszy Herberta w przekładzie na jezyk angielski, w: Język piękny dalekosięzny. Przekłady i międzynarodowa recepcja twórczości Zbigniewa Herberta, red. M. Heydel, E. Wójcik-Lesse, M. Woźniak, Kraków: Wydawnictwo UJ 2010, s. 201-211.

${ }^{56}$ Zob. Polityka a przektad, red. P. Fast, Katowice: Wydawnictwo Naukowe „Śląsk” 1996.

57 J. DERridA, Wieże Babel, tłum. A. Dziadek, w: Wspótczesne teorie przekładu, s. 375383. Zob. również T. BILCZEWSKI, Komparatystyka, s. 180-186.
} 
Dekonstrukcjonizm zatem, likwidując znaczenie woli autorskiej w odczytaniach tekstu [...] w praktyce znosi w ogóle problem hegemonii czy partnerstwa autora i tłumacza. [...] Wedle dekonstrukcjonistów, każde odczytanie może zostać zakwestionowane przez inne, antytetyczne. W tej sytuacji tłumacz mógłby czytać dowolnie i tworzyć takie znaczenie tekstu, jakie implikują wybrane przez niego konteksty ${ }^{58}$.

Krytyka przekładu wydaje się więc zbędna: skoro interpretacje i wybory tłumacza są zawsze słuszne - nie mogą być kwestionowane i oceniane. Tłumacz staje się najważniejszy w ogniwie translacyjnym, ponieważ jego status jest większy nie tylko od statusu autora oryginału, ale także od samego... Boga:

[S]truktura oryginału jest naznaczona przez wymóg bycia przełożoną, więc tym samym, prawnie, oryginał zadłuża się również u tłumacza. Oryginał jest pierwszym dłużnikiem, pierwszym petentem, wyczuwa brak i błąd - błaga o przekład. [...] Żądanie wymusza również istnienie dekonstruktora: Bóg, dając swoje imię, odwołuje się również do przekładu, i to nie tylko między językami, które zostały od razu pomnożone i pomieszane, ale przede wszystkim do przekładu swojego imienia [...]. Ponieważ Babel jest nieprzekładalne, Bóg opłakuje swoje imię. [...] Bóg zostaje zubożony o swoją siłę i swoje własne bogactwo, błaga o tłumacza ${ }^{59}$.

W ujęciu dekonstrukcjonistycznym wszystkie istniejące przekłady należałoby uznać za słuszne, a krytyk nie miałby prawa ganić żadnego tłumacza za odejścia od oryginału. Nie miałby prawa np. czynić zarzutów Adamowi Czerniawskiemu za przełożenie traktującej o rozbiorach Polski ballady Norwida Rozebrana jako utworu li tylko erotycznego ${ }^{60}$; nie miałby prawa również potępiać pierwszego przekładu Fatum pióra tego samego tłumacza za jego zbyt jednoznaczne odczytanie pierwowzoru.

Tłumacz cieszy się statusem drugiego autora na nowo piszącego oryginał także w feministycznych i postkolonialnych teoriach przekładu. Obydwie te teorie $\mathrm{w}$ swoim najbardziej radykalnym przejawie ${ }^{61}$ pozwalają na stosowanie

\footnotetext{
58 A. LEGEŻYŃSKA, Ttumacz jako drugi autor - dziś, s. 47.

59 J. DERRIDA, Wieże Babel, s. 383. Wyróżnienia rozstrzelonym drukiem autora, wytłuszczenie moje - A.B.-M.

60 Zob. A. BRAJERSKA-MAZUR, Rozebrana „Rozebrana”, „Akcent” 2005, nr 3 (101), s. 139-145 oraz TEJŻE, Czytanie Norwida, „Fraza” 2006, nr 3 (53), s. 312-314.

${ }^{61}$ Luise von Flotow w książce Translation and Gender. Translating in the „Era of Feminism" (Ottawa: University of Ottawa Press 1997) wyróżnia dwa feministyczne podejścia do języka i przekładu: reformistyczne i radykalne.
} 
technik interwencjonistycznych ${ }^{62}$ wobec tekstu źródłowego - tj. naginanie go (czasami na siłę) do mniejszościowego punktu widzenia i uwypuklanie perspektywy słabszej płci bądź słabszej kultury. W przekładzie feministycznym najczęściej chodzi o to, żeby „misją tłumaczki nie było uciszenie,

ale danie głosu, udostępnienie tekstów, które zadają trudne pytania i otwieraja nowe perspektywy. Jest bardzo ważne, by kobiety jako tłumaczki zagłębiały się w tkankę tekstów im przychylnych, jak i wobec nich antagonistycznych. Tłumaczki muszą stać się niezależnymi „opornymi” interpretatorkami, które nie tylko pozwalają antagonistycznym tekstom przemówić [...], ale i mówią razem z nimi, i umieszczaja je w szerszym kontekście poprzez wypowiedzi na ich temat i na temat procesu przekładu ${ }^{63}$.

Czasem takie tłumaczenie przybiera wręcz formę ,uprowadzenia” (hijacking) oryginału, czyli dodawania do niego nacechowanych ideologicznie treści, których w tekście źródłowym realnie nie ma - tak jak zrobiła to np. Susanne De Lotbiniere-Harwood, przekładając Lettres d'une autre Lise Gauvin z języka francuskiego na angielski. W przedmowie do przytoczonej książki tłumaczka otwarcie określiła swoją rolę jako społecznie zaangażowaną:

Moja praktyka tłumaczeniowa to działalność polityczna, której celem jest sprawienie, by język przemawiał za kobietami. Mój podpis pod przekładem oznacza, że użyłam w nim wszelkich możliwych strategii feministycznych, by ujawnić kobiecy język. Ujawnianie kobiecego języka oznacza, że kobiety są widziane i słyszane w prawdziwym świecie. A o to właśnie chodzi w feminizmie ${ }^{64}$.

Polityczna powinna być również działalność tłumaczy według przedstawicieli studiów postkolonialnych. Zdaniem Douglasa Robinsona w tłumaczeniu można odkryć:

- narzędzie kolonializacji,

\footnotetext{
${ }^{62}$ Takich jak: stosowanie komentarzy i przypisów, objaśnianie i dodawanie faktów, ,uprowadzanie" tekstu. Zob. L. von Flotow, Feminist Translation: Contexts, Practices and Theories, „TTR” 4(1991), nr 2, s. 69-84. Zob. również T. BILCZEWSKI, Komparatystyka, s. 186-216.

${ }^{63}$ C. MAIER, A Woman in Translation, Reflecting, „Translation Review” 1985, s. 34. Cyt. za: L. Chamberlain, Gender a metaforyka przektadu, tłum. A. Sadza, w: Wspótczesne teorie przektadu, s. 401.

${ }^{64}$ L. Gauvin, Letters from an Other, tłum. S. de Lotbinière-Harwood, Toronto: Three O’Clock Press 1989, s. 9. Tłumaczenie moje - A.B.-M.
} 
- świadectwo kolonializacji i dominacji kultury najeźdźcy nad kultura podporządkowaną,

- narzędzie de-kolonializacji ${ }^{65}$.

Przy tak nachylonej analizie za każdym razem dostrzega się w przekładzie polityczne zaangażowanie i zwalnia się go od przymusu podobieństwa do oryginału. Tłumaczenie wchodzi z pierwowzorem w grę, która odsłania dyskryminujące założenia tekstu źródłowego.

Tłumaczenie może korzystać z antykolonialnego potencjału, ponieważ [...] eksponuje granice tego, z czym radzi sobie dominujący język. Nie zawsze dzieje się tak, że dominujące terminy [...] podlegające przekładowi na język kultury podporządkowanej pozostają niezmienione przy okazji tłumaczenia. W rzeczy samej, sama postać dominującego terminu może ulec zmianie w procesie imitowania i wykorzystywania we wspomnianym kontekście podporządkowania [...]. Mimesis może doprowadzić do przemieszczenia, wyparcia pierwszego terminu, lub nawet ujawnić, że termin ten nie jest niczym innym jak tylko serią przemieszczeń i wyparć, co osłabia jakiekolwiek roszczenia do wyłączności na pierwotność i autentyczność znaczeń ${ }^{66}$.

Zarówno w feminizmie, jak i w postkolonializmie, powstają przekładowe „po-twory”, które są celowo nielojalne wobec oryginału. Pierwowzór nie znika z pola widzenia tłumacza i badacza, ale służy im do odsłaniania „,założeń dominujących dyskursów/ideologii” i wyrażania „czynnego oporu wobec hegemonicznej większości”, ${ }^{67}$.

Postkolonialna teoria przekładu skupia się nie tylko na zagadnieniach tożsamości i takich pojęciach jak ,różnica kulturowa”, „hybrydowość” czy „,władza”, jest bowiem przede wszystkim próbą ukazania tych - lub oddania głosu tym - którzy jako „zmarginalizowani/uciśnieni” (subaltern) głosu (języka) własnego nie posiadają. Teoria ta jest też często [...] gwałtownym sprzeciwem wobec uniformizacji i uproszczeń, jakie niesie z sobą przekład, i obroną tego, co specyficzne, unikatowe, marginalne $\mathrm{i}-\mathrm{w}$ swej istocie - ostatecznie nieprzekładalne ${ }^{68}$.

${ }^{65}$ D. RoBInson, Translation and Empire: Postcolonial Theories Explained, London and New York: Routledge 1998, s. 138. Tłumaczenie moje - A.B.-M.

${ }^{66} \mathrm{~J}$. ButLeR, Restaging the Universal. Hegemony and the Limits of Formalism, w: Contingency, Hegemony, Universality. Contemporary Dialogues on the Left, red. J. Butler, E. Laclau, S. Žižek, New York-London: Verso 2000, s. 14-15. Cyt. za: A. KowALCZE-PAwLIK, Uwolnić Charybdę, pokochać Skyllę. O po-tworności przektadu, „Przekładaniec” 21(2010), s. 195.

${ }^{67}$ A. Kowalcze-Pawlik, Uwolnić Charybde, s. 195. Zob. również T. BILCZEWSKI, Komparatystyka, s. 217-252.

68 T. MarkiewKa, Między wersetami. Przektad prozy Salmana Rushdiego w kontekście 
Większość współczesnych teorii związanych ze zwrotem kulturowym $\mathrm{w}$ translatoryce w mniejszym bądź większym stopniu albo posługuje się manipulacją (skopos, dekonstrukcjonizm, feminizm, postkolonializm), albo ją bada w przekładzie (Szkoła Manipulistów, teoria polisystemów). Większość również jest otwarta na szeroko pojęte konteksty oraz skupia się na roli, jaką tłumaczona literatura wywiera na kulturze przekładu, co „umożliwia spojrzenie na jej autonomiczność wobec oryginału, co z kolei pozwala postrzegać przekład inaczej niż tylko jako ze swej natury niedoskonałą kopię wyidealizowanego oryginału" ${ }^{69}$. Tekst źródłowy, jednym słowem, przestaje być miarą jakości tłumaczenia i lojalności tłumacza.

Zupełnie inny stosunek do pierwowzoru ma współczesna hermeneutyka oraz niektórzy badacze i filozofowie najczęściej związani z etycznym zwrotem w przekładoznawstwie. Podzielają oni szacunek do oryginału i wymagaja w stosunku do niego lojalności, choć z innych powodów.

Hermeneuci skupiają się na procesie odczytania pierwowzoru i uważają, że przekład jest sprawą interpretacji. Tłumacz powinien zachować lojalność w stosunku do oryginału, ponieważ spotkanie z tym, co obce, ma wielkie znaczenie dla narodowego języka i narodowej kultury ${ }^{70}$. Hermeneuci piszący o przekładzie to przede wszystkim filozofowie (Gadamer, Ricoeur), egzegeci-teolodzy (Schleiermacher) i filolodzy-lingwiści (Steiner, Paepcke, Stolze) ${ }^{71}$.

$\mathrm{Ku}$ etyce zwracają się także niektórzy współcześni badacze, studiujący historię przekładu, uwrażliwieni na jego społeczne i polityczne konsekwencje (Venuti, Berman, Chesterton, Pym). Według nich:

Etyczny wymiar pracy tłumacza ma się wyrażać [...] w szacunku dla głosu oryginału jako Innego, dla jego fundamentalnej obcości, niedającej się ująć w kategoriach należących do systemu literatury własnej. Przekład okazuje się sferą różnorako pojętej interwencji - politycznej czy społecznej - w obowiązujące style i dyskursy literatury docelowej. Konieczne jest zatem ujawnianie obecności podmiotu interwencji - tłumacza ${ }^{72}$.

postkolonialnej teorii translacji, „Przekładaniec” 27(2013), s. 133.

${ }^{69}$ P. Bukowski, M. Heydel, Przektad - jezzy - literatura, s. 22. Por. The Manipulation of Literature, s. 8.

${ }^{70}$ P. Bukowski, M. HeYdel, Przekład - jezyk - literatura, s. 26-32. Por. J. Grondin, Wprowadzenie do hermeneutyki filozoficznej, tłum. L. Łysień, Kraków: WAM 2007.

${ }^{71}$ P. Bukowski, M. HeYdel, Przektad - jezzyk - literatura, s. 28. Zob. również: Routledge Encyclopedia of Translation Studies, s. 130-133 - hasło: Hermeneutics; T. BILCZEWsKI, Komparatystyka, s. 115-127.

72 M. Heydel, Zwrot kulturowy, s. 23. Zob. A. Berman, Przektad jako doświadczenie 
Nie tylko tłumacz ma być widzialny ${ }^{73}$ - widoczne powinny być również jego decyzje, ponieważ odbiorcy mają prawo być świadomi, jakie uwarunkowania i systemy wartości wnosi on do tekstu docelowego. Tłumacz jest współtwórcą dialogu międzykulturowego, mediatorem, którego praca kształtuje przestrzeń społeczną i ideologiczną ${ }^{74}$. Stąd ważne jest, by z jednej strony uwidaczniać, co na niego wpływa, a z drugiej, by zachęcać go do „tworzenia przekładów adekwatnych pod względem wyrazu, opartych na prawdziwym podobieństwie wobec oryginału, a także do budowania wzajemnego zaufania i minimalizowania nieporozumienia między uczestnikami zapośredniczonej przez niego komunikacji w tłumaczeniu"75.

Szacunek do Innego (a także, paradoksalnie, do czytelnika przekładu) sprawia więc, że tłumacze mają być lojalni wobec oryginału i jego autora. Mają stosować strategię wyobcowania (wracamy tu do postulatu prekursora współczesnej hermeneutyki - Schleiermachera), a nie przyswojenia. Jeśli chodzi o wymóg lojalności tłumacza, przekładoznawstwo zatoczyło więc szerokie koło. Przesuwając się po kolejnych elementach schematu translacyjnego i dodając do niego nowe - powrócono w końcu do oryginału i przywrócono mu najważniejszą pozycję. Paradoksalnie spowodowały to te same aspekty i konteksty kulturowe, które go z niej zrzuciły.

Myślę, że obok tak ważnych kwestii, jak uświadamianie wagi kulturowego pośrednictwa tłumacza (mniej lub bardziej skażonego różnego rodzaju wpływami), istotne są tu jeszcze inne powody, dla których lojalność tłumacza powinna być skierowana ku oryginałowi. Pokazanie inności Innego otwiera na obcą kulturę i odmienne postrzeganie świata, co w dobie ksenofobii i nacjonalizmów jest ożywcze i pożądane. Poza tym, sama przyczyna tłumaczenia staje się wtedy logiczniejsza, bo przecież po to przekłada się dzieła obce, by dowiedzieć się, dlaczego są cenione w kulturach, z których pochodzą, a bez wyobcowania i lojalności wobec pierwowzoru tego się nie osiągnie. Ciekawość, szerokość i otwar-

obcego, w: Wspótczesne teorie przektadu, s. 247-264; L. VenUTI, Przektad, wspólnota, utopia, w: Wspótczesne teorie przektadu, s. 265-294.

73 L. VenutI, The Translator's Invisibility.

74 „The Translator” 2001, no 7 (2), numer specjalny: The Return to Ethics, red. A. Pym; zob. również T. Hermans, Translation, Ethics, Politics, w: The Routledge Companion to Translation Studies, red. J. Munday, London-New York: Routledge 2009, s. 93-105.

${ }^{75}$ M. Heydel, Zwrot kulturowy, s. 28. Zob. A. ChESTERMAn, Ethics of Translation, w: Translation as Intercultural Communication. Selected Papers from EST Congress, Prague 1995, red. M. Snell-Hornby, Z. Jettmarová i K. Kaindl, Amsterdam-Philadelphia: John Benjamins 1997, s. 147-157; TEGOŻ, Proposal for a Hieronymic Oath, „The Translator” 2001, No. 7 (2), s. $139-154$. 
tość myślenia, a także tolerancyjność i życzliwość także przemawiają więc za wiernością przekładu $\mathrm{w}$ stosunku do oryginału.

Z tych przyczyn w Polsce obok i w sprzeczności do niektórych współczesnych teorii przekładu detronizujących oryginał i/lub zezwalających na jego dowolne interpretacje, stoją założenia metody kateny oraz przemyślenia Jadwigi Puzyniny na temat tłumaczenia. Służąca do oceny jakości i wierności przekładu metoda kateny, o której powiązaniu z dominanta semantyczna Stanisława Barańczaka $^{76}$ oraz katenami ${ }^{77}$ stosowanymi przez Ojców Kościoła obszerniej pisałam w innych pracach $^{78}$, jest zbieżna $\mathrm{z}$ wcześniejszymi ustaleniami profesor Jadwigi Puzyniny ${ }^{79}$. Badaczka, recenzując niemieckojęzyczne przekłady utworów Norwida, przyjęła zasady, które także obowiązują w katenie. Mianowicie:

1. Interpretacja oryginału leży u podstaw jego przekładu i „dotyczy zazwyczaj zarówno jego formy, jak i znaczenia, a także świata przedstawionego w danym utworze" ${ }^{\prime 80}$;

2. Przekład ,jest powiązany związkami przyczynowo skutkowymi z interpretacją w obu jej znaczeniach - sam jednak interpretacją nie jest”, ponieważ „może być tylko wyrazem pewnego rozumienia tekstu”,

3. „Przekład utworu literackiego jest tym lepszy, im lepsza, pełniejsza interpretacja leży u jego podstaw”. Stąd ważna jest interpretacja „docierająca do sensów przekazywanych przez autora” oraz oddająca to, „co składa się na

${ }^{76}$ Zob. S. BARAŃCZAK, Maty, lecz maksymalistyczny manifest translatologiczny, w: TEGOŻ, Ocalone w ttumaczeniu, wyd. 3, Kraków: a5 2004, s. 20 i 35-36.

77 J.M. SZYMUSIAK, M. STAROWIEYSKI, Stownik wczesnochrześcijańskiego piśmiennictwa, Poznań: Księgarnia Świętego Wojciecha 1971, s. 248; B. Altaner, A. Stuiber, Patrologia, Warszawa: PAX 1990, s. 662 nn.; Praktyczny słownik biblijny, red. A. Grabner-Haider, przeł. i oprac. P. Pachciarek, Warszawa: PAX 1994, s. 546; B. BURDZIEJ, Super Flumina Babylonis. Psalm 136 (137) w literaturze polskiej XIX-XX w., Toruń: Wydawnictwo Naukowe UMK 1999, s. 31-34.

${ }^{78}$ Zob. A. BRAJERSKA-MAZUR, O angielskich ttumaczeniach utworów Norwida, Lublin: TN KUL 2002; TEJŻE, Katena and Translations of Literary Masterpieces, „Babel” 2005, vol. 51, s. 16-30; TEJŻE, O przektadzie na jezzk angielski wierszy Norwida „Śmierć”, „Do Zeszłej...” „Finis”, „Pamiętnik Literacki” XCVII (2006), z. 4, s. 229-237; TEJŻE, Norwid, „Spartakus" i Internet, w: Strona Norwida. Księga poświęcona profesorowi Stefanowi Sawickiemu, red. P. Chlebowski [i in.], Lublin: TN KUL 2008, s. 7-28; TEJŻE, Ten Commandments for the Translation of the Works of Cyprian Norwid (and what came from them, or, on the translations of Danuta Borchardt), „The Polish Review” LIII (2008), No. 4, s. 495-540; TEJŻE, Katena a przekład wspótczesnej poezji polskiej, w: Translatio i literatura, red. A. Kukułka-Wojtasik, Warszawa: Wydawnictwo UW 2011, s. 27-34.

${ }^{79}$ J. PUZYNINA, Język - interpretacja - przekład, „Studia Norwidiana” 11(1993), s. 31-51.

${ }^{80}$ Tamże, s. 31-32.

${ }^{81}$ Tamże, s. 32, przyp.1. 
poetycki model świata: rym, rytm, całą muzykę wiersza, onomatopeje, aliteracje i inne środki języka poetyckiego" ${ }^{82}$;

4. „Zarówno interpretacja, jak i przekład podlegają wartościowaniu” - to znaczy, że interpretacja jest tym lepsza, im m.in.: „,szerszy horyzont znaczeniowy uwzględnia jego interpretator” $\mathrm{i}$ im ,lepiej potrafi on w tym horyzoncie [...] wyodrębnić to, co istotne, co wpływa na inne poziomy tekstu" ${ }^{\prime 3}$.

Przekład może być więc oceniany i porównywany z oryginałem, wobec którego powinien być wierny dzięki wnikliwej interpretacji pierwowzoru. Dogłębna analiza tekstu źródłowego ma dopomóc tłumaczom w zachowaniu lojalności wobec oryginału i stworzeniu przekładu jak najbardziej do niego podobnego. Wszystko poza tym interpretacyjno-tekstowo-kulturowo-językowym procesem, wszystkie konteksty społeczne, polityczne i ideologiczne są ważne, ale w hierarchii ważności powinny istnieć obok (lub na dalszych miejscach) schematu translacyjnego. Jeśli traci się z oczu oryginał jako najbardziej istotny punkt odniesienia w translacji i coraz bardziej zwraca się uwagę na wywierane na nią wpływy - rozmyte zostaje sedno przekładu: poznanie, zrozumienie i otwarcie na Obcego. Wszystko wykraczające poza relację: oryginał - przekład jest po prostu dookolne i uzupełniające, a traktowane jako centralne staje się manipulacją.

\section{BIBLIOGRAFIA}

BARAŃCZAK S.: Mały, lecz maksymalistyczny manifest translatologiczny, w: TEGOŻ, Ocalone w tłumaczeniu, wyd. 3, Kraków: a5 2004.

BILCZEWSKI T.: Komparatystyka i interpretacja. Nowoczesne badania porównawcze wobec translatologii, Kraków: Universitas 2010.

BOROWY W.: Dawni teoretycy tłumaczeń, w: O sztuce tłumaczenia, red. M. Rusinek, Wrocław: Ossolineum 1955.

BRAJERSKA-MAZUR A.: O angielskich tłumaczeniach utworów Norwida, Lublin: TN KUL 2002.

Bukowski T., Heydel M.: Przekład - język - literatura, w: Współczesne teorie przekładu. Antologia, red. P. Bukowski i M. Heydel, Kraków: Znak 2009.

EVEN-ZoHAR I.: Miejsce tłumaczonej literatury w polisystemie literackim, w: Współczesne teorie przekładu. Antologia, red. P. Bukowski i M. Heydel, Kraków: Znak 2009.

GENTZLER E.: Contemporary Translation Theories, wyd. 2, Clevendon: Multilingual Matters 2001.

GRUCZA F.: Zagadnienia translatoryki, w: Glottodydaktyka a translatoryka, red. F. Grucza, Warszawa: Wydawnictwa Uniwersytetu Warszawskiego 1981.

GRUCZA F.: Wyodrębnienie się, stan aktualny i perspektywy świata translacji oraz translatoryki, „Lingua Legis” 1998, nr 6, s. 2-12.

GRZEGORCZYK P.: Problematyka tłumaczeń, w: O sztuce tłumaczenia, red. M. Rusinek, Wrocław: Ossolineum 1955.

\footnotetext{
82 Tamże, s. 32-33.

83 Tamże, s. 32.
} 
LEGEŻYŃSKA A.: Tłumacz jako drugi autor - dziś, w: Przekład literacki: teoria, historia, współczesność, red. A. Nowicka-Jeżowa i D. Knysz-Tomaszewska, Warszawa: PWN 1997, s. 40-50.

Polityka a przekład, red. P. Fast, Katowice: Wydawnictwo Naukowe „Śląsk” 1996.

The Manipulation of Literature: Studies in Literary Translation, red. Th. Hermans, London: Croom Helm 1985.

VenUTI L.: Rethinking Translation. Discourse, Subjectivity, Ideology, London-New York: Routledge 1992.

\section{LOJALNOŚĆ TŁUMACZA}

$$
\text { St res z c z e n i e }
$$

W artkule zostają omówione zmieniające się teorie przekładoznawcze, które lokują wierność tłumaczy w różnych elementach procesu translacyjnego. Raz wymaga się od nich wierności wobec autora tekstu źródłowego, innym razem wobec oryginału lub kolejno: czytelników pierwowzoru, kultury wyjściowej, kultury docelowej, odbiorcy przekładu, zleceniodawcy przekładu, norm docelowych itp. Raz traktuje się tłumacza jako kopistę, innym razem pozwala mu się ingerować w tekst i być jego drugim autorem (czasem ważniejszym niż twórca pierwowzo$\mathrm{ru!).} \mathrm{Te} \mathrm{zmieniające} \mathrm{się} \mathrm{normy} \mathrm{translatoryczne} \mathrm{są} \mathrm{opisane} \mathrm{w}$ artykule $\mathrm{z}$ punktu widzenia etyki słowa, dlatego najbardziej uwypuklona została w nim jedna $\mathrm{z}$ nowszych teorii przekładu tj. „Szkoła Manipulistów”. Od lojalności tłumacza (wobec kogo? czego?) zależy kształt przekładu, który z kolei wpływa na rzesze czytelników, ich poglądy i postawy życiowe. Gdzie więc tłumacz ma tę lojalność lokować, wobec kogo i czego ma być wierny? W artykule zostają także udzielone odpowiedzi na te pytania.

Słowa kluczowe: lojalność tłumacza; zwrot kulturowy w translatoryce; Szkoła Manipulistów; nowoczesne teorie translacyjne.

\section{TRANSLATORS' LOYALTY}

\section{S u m m a r y}

The author discusses various changing translational theories which place the translator's loyalty in different elements of the translational process. Sometimes loyalty towards the author of the source text is demanded of them, and other times faithfulness towards the original work or to its readers, source culture, target culture, target recipients, translation commissioner, norms of the target culture etc. is required. Sometimes translators are treated like mere copyists, and other times as second authors (often even more important than the creators of the original texts). The article describes these changing norms from an ethical point of view, focusing on one of the most modern theories - the Manipulation School. A translator's loyalty (to what and whom?) influences the shape of the translation, which, in turn, affects its readers, their views and attitudes. And so, where should translators place their loyalty, to whom and to what should they be faithful? These questions require answers and answers are provided.

Key words: translators; loyalty; cultural turn in translation studies; the Manipulation School; modern translational theories. 